\title{
Artemisia capillaris Thunb. inhibits melanin synthesis activity via ERK-dependent MITF pathway in B16/F10 melanoma cells
}

\author{
Evelyn Saba ${ }^{1}$, Mi Ju Oh${ }^{1}$, Yuan Yee Lee ${ }^{1}$, Dongmi Kwak ${ }^{1}$, Suk Kim², Man Hee Rhee ${ }^{1, *}$ \\ ${ }^{1}$ Department of Veterinary Medicine, College of Veterinary Medicine, Kyungpook National University, Daegu 41566, Korea \\ ${ }^{2}$ Department of Veterinary Medicine, College of Veterinary Medicine, Gyeongsang National University, Jinju 52828, Korea
}

(Received: November 30, 2017; Revised: January 11, 2018; Accepted: January 25, 2018)

\begin{abstract}
Genus Artemisia occurs as a hardy plant and has a wide range of culinary and medicinal features. In this study, we aimed to describe the melanin inhibitory activity of one Artemisia species, i.e., Artemisia capillaris Thunb. Ethanol extracts of fermented Artemisia capillaris (Art.EtOH.FT) and non-fermented Artemisia capillaris (Art.EtOH.CT) were tested for their ability to inhibit tyrosinase activity and melanin pigmentation. Both extracts showed dose-dependent inhibition against $\alpha$-melanocyte stimulating hormone-stimulated melanin formation and tyrosinase activity, without cytotoxicity. At $100 \mu \mathrm{g} / \mathrm{mL}$, both extracts showed greater inhibition than kojic acid, the positive control. Protein expressions of microphthalmia-associated transcription factor (MITF), tyrosinase (TYR), tyrosinase-related protein 1 (TRP-1), and tyrosinase-related protein 2 (TRP-2) at the transcriptional level were determined by using real-time and semi-quantitative polymerase chain reaction. To complete the mechanistic study, presences of upstream elements of MITF, the phosphorylated-extracellular signal-regulated kinase (p-ERK), and phosphorylated-mitogen-activated protein kinase kinase (p-MEK) were confirmed by using western blot analysis. Expressions of p-TYR, p-TRP-1 and p-TRP2, downstream factors for p-ERK and p-MITF, were translationally inhibited by both extracts. Art.EtOH.FT induced more potent effects than Art.EtOH.CT, especially signal transduction effects. In summary, Artemisia capillaris extracts appear to act as potent hypopigmentation agents.
\end{abstract}

Keywords: Artemisia capillaris, hypopigmentation, melanin inhibition, tyrosinase

\section{Introduction}

Variety in the skin colour of different human races is attributed to the amount of melanin pigment present in the skin. Melanin is basically the compound that gives colour to our skin in various shades depending upon its concentration [2]. It is formed by a process called melanogenesis in which $\alpha-$ melanocyte stimulating hormone ( $\alpha-\mathrm{MSH})$ binds to its receptor i.e., melanocortin 1 receptor (MC1R) which elevates the levels of cyclic adenosine monophosphate (cAMP) that activates microphathalamia-associated transcription factor (MITF) via different pathways like extracellular signal-regulated kinase (ERK), protein kinase B and cAMP response element binding protein causing its degradation. This affects the rate limiting step of this process i.e., tyrosinase (TYR). TYR catalyses the conversion of tyrosine to L-3,4-dihydroxyphenylalanine (L-DOPA) that forms melanin later. There are other two factors that are affected down stream of MITF and TYR like tyrosinase-related protein 1 (TRP-1) and tyrosinase-related protein 2 (TRP-2) whose activation leads to melanogenesis [12-14, 34].
Genus Artemisia is one of the most important genera in Asteraceae family and is widely found throughout the world. Artemisia capillaris Thunb., which is one of the species of genus Artemisia is widely used traditional medicinal plant and extensively used food supplement. Artemisia capillaris (A. capillaris) that is also called 'Yin Chen Hao' is extensively used in China for over 2,000 years particularly for its remarkable hepatoprotective effects like in jaundice, hepatitis and gall bladder diseases [1, 5, 7, 10, 16, 19, 30]. Many biologically active metabolites in it like coumarins, flavonoids, sterol glycosides, essential oils and polyacetylenes have been reported to exhibit a wide range of biological activities like, antioxidant, anti-malarial, anti-cancerous, antiviral and anti-fungal [3, 17, 20, 23, 24, 32]. Moreover, it is also applied externally on the head for relief from headaches [4].

Up till now there has been no study made to elucidate the anti-melanogenic effects of this $A$. capillaris. Therefore, we checked the TYR inhibition and melanin production inhibition via the mechanistic study of pathway involved in this process. Our results have shown that the two sample extracts of $A$. capillaris i.e., fermented and non-fermented type showed

*Corresponding author

Tel: +82-53-950-5967, Fax: +82-53-950-5955

E-mail: rheemh@knu.ac.kr 
remarkable inhibition in TYR activity and also showed decreased melanin content via the ERK activated MITF degradation pathway especially in the fermented type. Further studies in future on this extract can guarantee its usage in the cosmetic industry as a skin whitening agent.

\section{Materials and Methods}

\section{Chemicals and reagents}

Dulbecco's modified Eagle's medium (DMEM) (Korea), fetal bovine serum (FBS) (WelGene, Korea), streptomycin and penicillin (Lonza, USA), TRIzol reagent (Invitrogen, USA), oligo dT (Bioneer, Korea), MITF, TYR, TRP-1, TRP-2 and $\beta$-actin primers were obtained from Bioneer. 3-(4,5-dimethylthiazol-2-yl)-2,5-diphenyltetrazoliumbromide (MTT) was purchased from Sigma-Aldrich (USA). Specific antibodies used against phospho- and/or total form of mitogen-activated protein kinase kinase (MEK), ERK, $\beta$-actin and secondary antibody rabbit HRP linked were purchased from Cell Signalling Technology (USA). Antibodies for phospho- MITF, TYR, TRP-1 and TRP-2 were obtained from Santa Cruz Biotechnology (USA). TYR from mushroom and L-DOPA were purchased from Sigma (USA). All other reagents were of local analytical grade.

\section{Sample preparation}

A. capillaris fermented and non-fermented dried samples were obtained from enzyme LAPA (Korea) and fermented according to Saba et al. [29]. They were then extracted with $70 \%$ ethanol and filtered using a Whatman filter paper (pore size $185 \mathrm{~mm}$; Sigma-Aldrich). The filtrate was then converted to powder form using freeze drying. Later they were dissolved in dimethyl sulfoxide (DMSO) and used according to experimental design dosages.

\section{Gas chromatography mass spectrometry (GC-MS)}

GC-MS was carried out for the fermented and non-fermented Artemisia samples using $100 \mathrm{mg}$ of powered sample. Agilent technology 7890A Gas chromatograph systems (Agilent Technologies, USA) attached to XLMSD-5975C instrument with electrospray ionization mode was harvested. The component's percentage was calculated by comparing its average peak to the total area under curve. The component with highest percentage was acetic acid (40\%) in fermented sample with the next being deoxy arteminisin (7\%). The similar components were also elevated in non-fermented sample but their concentrations were lower than fermented type.

\section{Cell line}

Murine melanoma cell line B16/F10, originating from American Type culture collection was cultured in DMEM supplemented with $8 \%$ FBS (WelGene) and $100 \mathrm{IU} / \mathrm{mL}$ penicillin and $100 \mu \mathrm{g} / \mathrm{mL}$ streptomycin sulfate (Lonza). The incubating conditions were humidified in $5 \% \mathrm{CO}_{2}$ at $37^{\circ} \mathrm{C}$.

\section{Cell-free TYR inhibition assay}

The assay was performed with slight modifications as previously described [33]. Briefly $10 \mu \mathrm{L}$ of $A$. capillaris fermented and non-fermented samples was put in 96-well in triplicates and mixed with $60 \mu \mathrm{L}$ of $50 \mathrm{mmol} / \mathrm{L}$ phosphate buffer on ice (pH 6.8). Then $20 \mu \mathrm{L}$ of $0.9 \mathrm{mg} / \mathrm{mL}$ L-DOPA was added to each well. Finally $10 \mu \mathrm{L}$ of mushroom TYR was added in each well and the plate was incubated at $27^{\circ} \mathrm{C}$ for $10 \mathrm{~min}$. After incubation, the amount of dopachrome production was determined spectrophotometrically at $450 \mathrm{~nm}$ by a microplate reader (Versamax microplate reader; Molecular devices, USA). Kojic acid in this experiment was taken as a positive control.

\section{Cell viability assay}

To determine the cytotoxic effects of $A$. capillaris extracts, cell viability assay was done using MTT reagent which was added to culture medium at a final concentration of $0.1 \mathrm{mg} /$ $\mathrm{mL}$. After $4 \mathrm{~h}$ of incubation at $37^{\circ} \mathrm{C}$ in $5 \% \mathrm{CO}_{2}$, the resulting violet coloured crystals were dissolved in DMSO 100 $\mu \mathrm{L} /$ well and absorbance values were measured at $560 \mathrm{~nm}$.

\section{Melanin inhibition assay}

The B16/F10 cells were seeded in the 6-well culture plate at a density of $2.5 \times 10^{3}$ cells/well and then incubated for 5 days. After the cells reached the desired confluency, they were treated with $A$. capillaris samples and then stimulated with $\alpha-\mathrm{MSH}$. The cells were then incubated again for 3 days and then harvested using $0.25 \%$ trypsin-EDTA solution and transferred to $1.5 \mathrm{~mL}$ microcentrifuge tubes. The tubes were then centrifuged at $10,000 \times \mathrm{g}$ for $10 \mathrm{~min}$ and pellet was dissolved in $2 \mathrm{~mol} / \mathrm{L} \mathrm{NaOH}$ for $15 \mathrm{~min}$ at $60^{\circ} \mathrm{C}$. Later this dissolved mixture was transferred to 96-well plates and absorbance was measured at $450 \mathrm{~nm}$ with a microplate reader (Versamax microplate reader; Molecular devices). The absorbance was compared to the synthetic standard melanin curve (Sigma).

RNA extraction and real-time polymerase chain reaction (PCR)

Total RNA was extracted from the B16/F10 cells after they were treated with $A$. capillaris extracts and stimulated with $\alpha$-MSH using TRIzol according to Manufacturer's instructions. Total RNA $(2 \mu \mathrm{g})$ was annealed with Oligo dt (Bioneer) for $10 \mathrm{~min}$ at $70^{\circ} \mathrm{C}$ and cooled for $5 \mathrm{~min}$ on ice, reverse transcribed using reverse transcriptase pre-mix (Bioneer) in $20 \mu \mathrm{L}$ of reaction mixture and run for $90 \mathrm{~min}$ at $42.5^{\circ} \mathrm{C}$ using thermal cycler. The reactions were terminated at $95^{\circ} \mathrm{C}$ for 5 $\min$ to inactivate the reverse transcriptase. The reverse transcription polymerase chain reaction was performed using aliquots of cDNA obtained from RT reaction in a PCR premix (Bioneer). The PCR products were then electrophoresed on $1 \%$ agarose gel stained with ethidium bromide and visualized using ImageQuant LAS 500 (GE health care life sciences, Korea). The intensity of band densities was normalized for corresponding GAPDH, which is housekeeping gene used 
Table 1. Oligonucleotide sequences of primers used for real-time polymerase chain reaction

\begin{tabular}{cll}
\hline \hline Genes & Direction & \multicolumn{1}{c}{ Oligonucleotide sequence $\left(5^{\prime}-3^{\prime}\right)$} \\
\hline \multirow{2}{*}{ MITF } & Forward & 5'-CATCGCATAAAACCTGATGGC-3' \\
& Reverse & 5'-GTCGTCACCCTGAAAATCCTAACT-3' \\
TYR & Forward & 5'-TGGGTCATCTTGTCTTGCTG-3' \\
& Reverse & 5'-TACCATCTGTTGTGGCTGGA-3' \\
TRP-1 & Forward & 5'-ACCCACACTGTGCCCATCTA-3' \\
& Reverse & 5'-CGGAACCGCTCATTGCC-3' \\
TRP-2 & Forward & 5'-GTCCAATAGGTGCGTTTTCC-3' \\
& Reverse & 5'-ACCCATTTGTCTCCCAATGA-3' \\
\hline
\end{tabular}

MITF, microphathalamia-associated transcription factor; TYR, tyrosinase; TRP-1, tyrosinase-related protein 2; TRP-2, tyrosinase-related protein 2 .

as an RNA internal standard and ratios were compared. Moreover, PCR product was also analysed via real-time PCR (Bio-Rad CFX96 Real-Time systems; Bio-Rad Laboratories, USA) using primers sequence is given in Table 1 .

\section{Western blot analysis}

B16/F10 cells were treated or left untreated with both $A$. capillaris extracts $(25-100 \mu \mathrm{g} / \mathrm{mL})$ in the presence or absence of $\alpha$-MSH $(10 \mu \mathrm{M})$. Cytosolic and nuclear proteins were extracted according to the instructions of NE-PER Nuclear and cytosolic extraction reagents (Thermo Scientific, Korea). Proteins were then measured using PRO-MEASURE Protein Measurement Solution (iNtRON Biotechnology, Korea). They were then separated by $10 \%$ polyacrylamide gels through SDS-PAGE and transferred onto polyvinylidene fluoride (PVDF) membranes (Immobilion-P; Millipore, USA). Nonspecific binding on the PVDF membranes was minimized with a blocking buffer containing 5\% non-fat dry milk and $0.1 \%$ Tween-20 in tris-buffered saline. The membranes were then incubated with specific primary antibodies overnight at $4^{\circ} \mathrm{C}$ followed by $1 \mathrm{~h}$ incubation with horseradish peroxidase-conjugated anti-rabbit antibody (1:3,000 dilution). Bound antibodies were visualized using enhanced chemiluminescence (Supex, Korea) and images were analysed using ImageJ software. $\beta$-actin was taken as an internal control.

\section{Statistical analysis}

Data were presented as mean \pm SEM. One way ANOVA and Dunnett's test were applied for the statistical evaluation of data. Statistical analyses with $p<0.01, p<0.005$ and $p<$ 0.001 were considered significant.

\section{Results}

\section{A. capillaris extracts inhibited TYR activity in cell-free system}

The rate limiting step in melanogenesis processes is the enzyme TYR $[27,36]$, therefore we geared to investigate if $A$. capillaris extracts have effect on this enzyme. Using the cellfree system with mushroom TYR, we found that both the fermented and non-fermented types of $A$. capillaris extracts
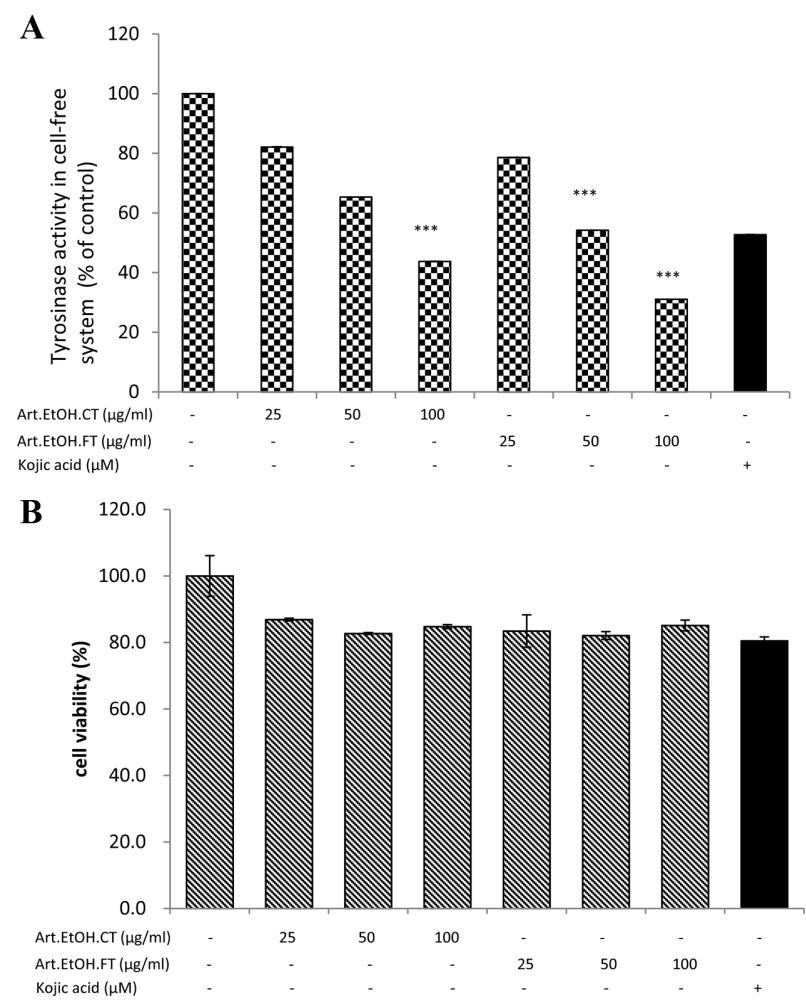

Fig. 1. Inhibition of mushroom TYR activity by Artemisia capillaris (A. capillaris) extracts. Both A. capillaris extracts inhibited the mushroom TYR activity, ${ }^{* * *} p<0.001$ when compared with untreated group (A). No cytotoxicity was observed for both extracts in B16/F10 cells (B).

inhibited TYR activity in dose dependent manner as shown in Figure 1A. Moreover, since many herbal extracts possess a variety of compounds in them, that can incur cytotoxicity, for this purpose we checked the cytotoxicity of doses used in our study for inhibition of melanogenesis, and none of the dosage used showed any toxic effects on B16/F10 cells (Fig. 1B).

Melanin content suppression by $\boldsymbol{A}$. capillaris extracts Melanin is the natural pigment that gives colour to our skin. However, if it is excreted in higher levels than the threshold by melanocytes, it can lead to benign or malignant 


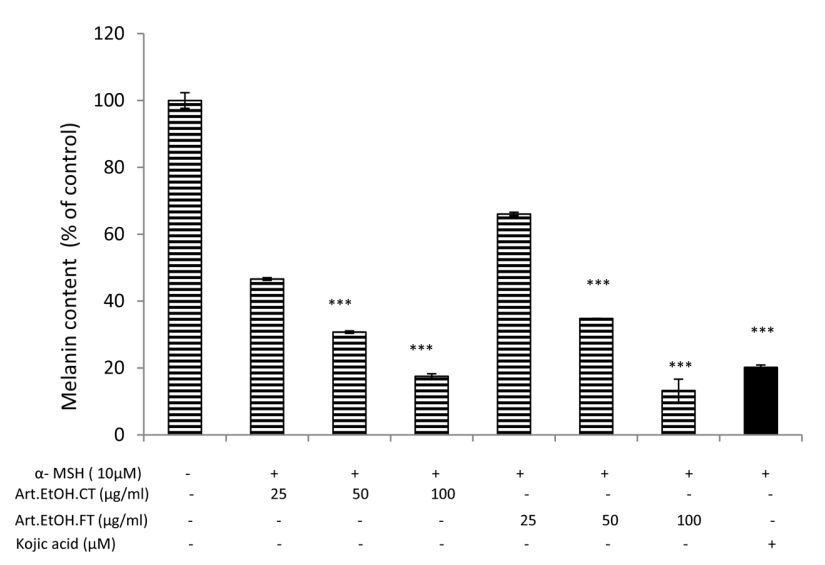

Fig. 2. Suppression in melanin content by $A$. capillaris extracts. Melanin content in crude lysates was suppressed by both $A$. capillaris extracts when $\mathrm{B} 16 / \mathrm{F} 10$ cells were stimulated with $\alpha$ melanocyte stimulating hormone $(\alpha-\mathrm{MSH}) .{ }^{* * *} p<0.001$ when compared with control.

form of cancers [15]. Considering this matter we checked the effect of $A$. capillaris extracts on B16/F10 cells when they were stimulated with $\alpha$-MSH for melanin secretion. As shown in Figure 2, both extracts when compared with control, suppressed the melanin contents in the cells in a dose dependent manner.

Effects of $A$. capillaris extracts on the mRNA expression of MITF and TYR related proteins

Above results elaborated the effects of $A$. capillaris extracts on TYR and melanin contents. However, it is important to understand the underlying mechanisms both at transcriptional and translational levels by which these extracts are elucidating their inhibitory effects. The mRNA expressions as shown in Figure $3 \mathrm{~A}$ and $\mathrm{B}$ by reverse transcriptase PCR and real-time PCR for MITF, TYR, TRP-1 and TRP-2 showed a dose dependent decrease with the increase in extracts concentration.

A. capillaris extracts exerted their anti-melanogenic effects via the mitogen activated protein kinase (MAPK)/ ERK dependent MITF pathway

There have been many reports in past that indicate ERK pathway's involvement in the melanogenesis inhibition through degradation of MITF [37]. This led us to explore the upstream pathways that might be involved in the degradation of MITF leading to inhibition of melanin production. The results of immunoblotting showed that $A$. capillaris extracts activated the phospho-MEK that is the upstream regulator of ERK. In addition, they also activated the levels of phospho-ERK in a dose dependent manner (Fig. 4A). Furthermore the results also showed that both extracts exerted their anti-melanogenic activities via the ERK dependent MITF pathway since they also inhibited the phosphorylation of all four factors for melanin synthesis i.e., p-MITF, p-TYR, p-TRP-1 and p-TRP2 with fermented type being more potent than non-fer-

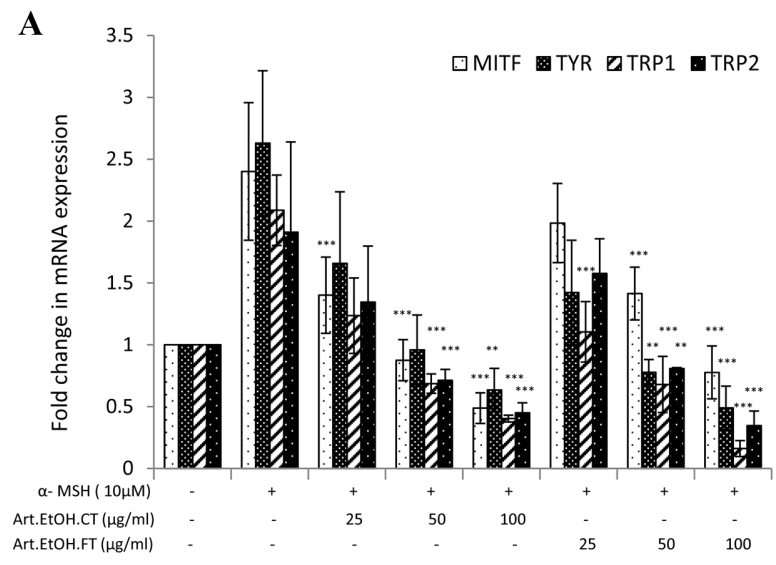

B

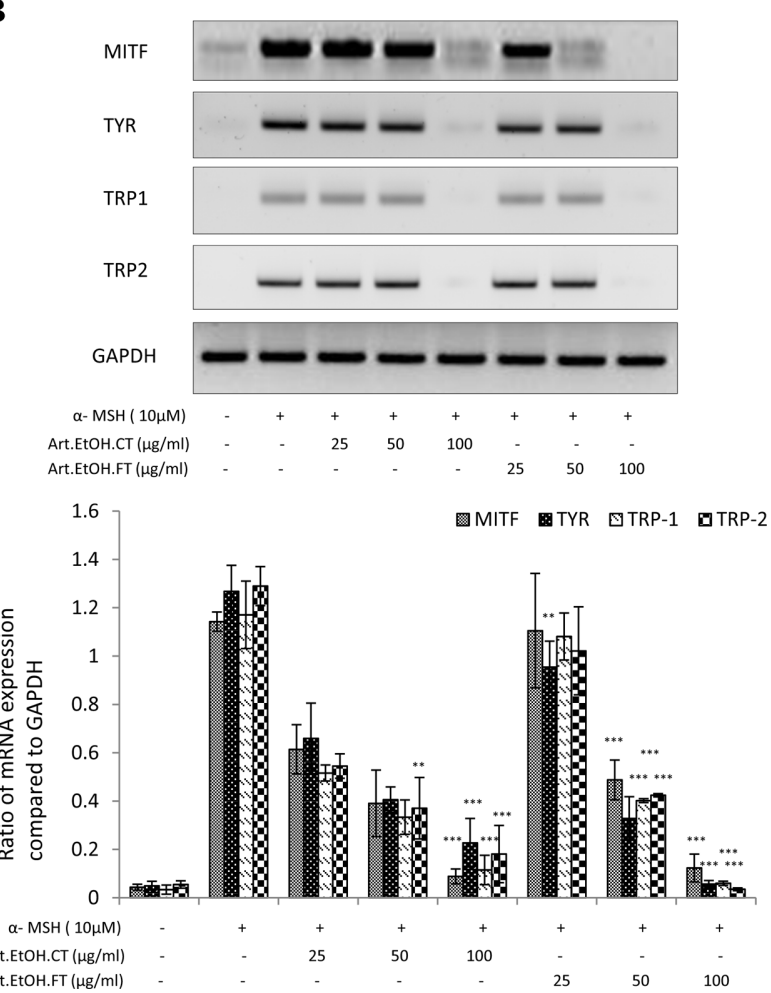

Fig. 3. Depressed expression of the MITF pathway genes by $A$. capillaris extracts. B16/F10 cells were seeded in 6 well plates and treated with indicated concentrations of Artemisia samples and then stimulated with $\alpha-\mathrm{MSH}(10 \mu \mathrm{M})$. Later RNA was extracted and MITF, TYR, TRP-1 and TRP-2 expression levels were checked by real-time polymerase chain reaction (RT-PCR) (A) and also by quantitative RT-PCR (B). GAPDH was taken as internal control and all values were compared against it. ${ }^{* * *} p<0.001$ and ${ }^{* *} p<0.05$ were considered as statistically significant against $\alpha$-MSH treated group only.

mented type (Fig. 4B).

\section{Discussion}

The basal layer of epidermis contains specialized cell 
A
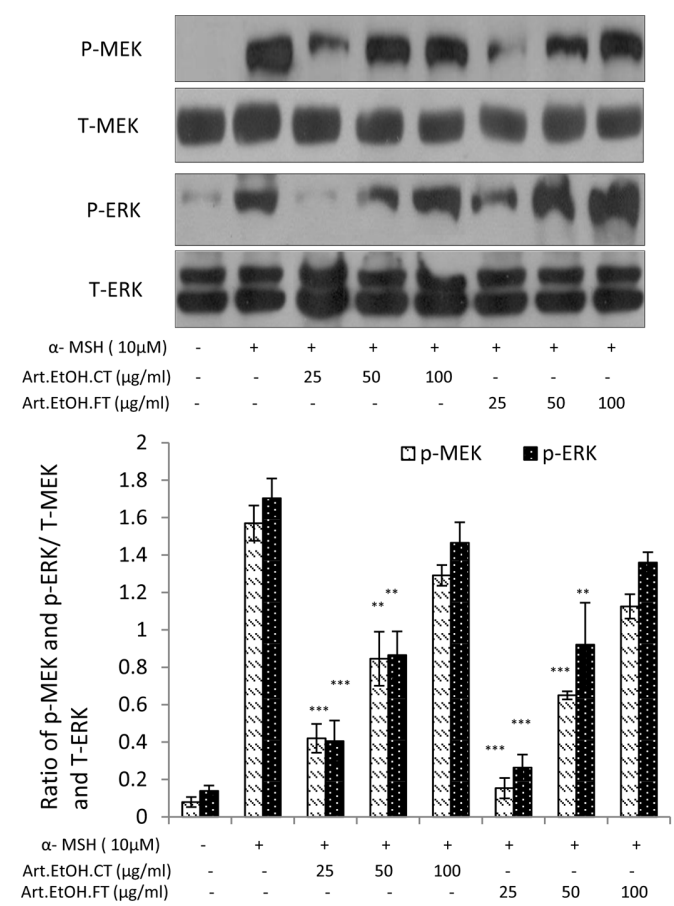

B
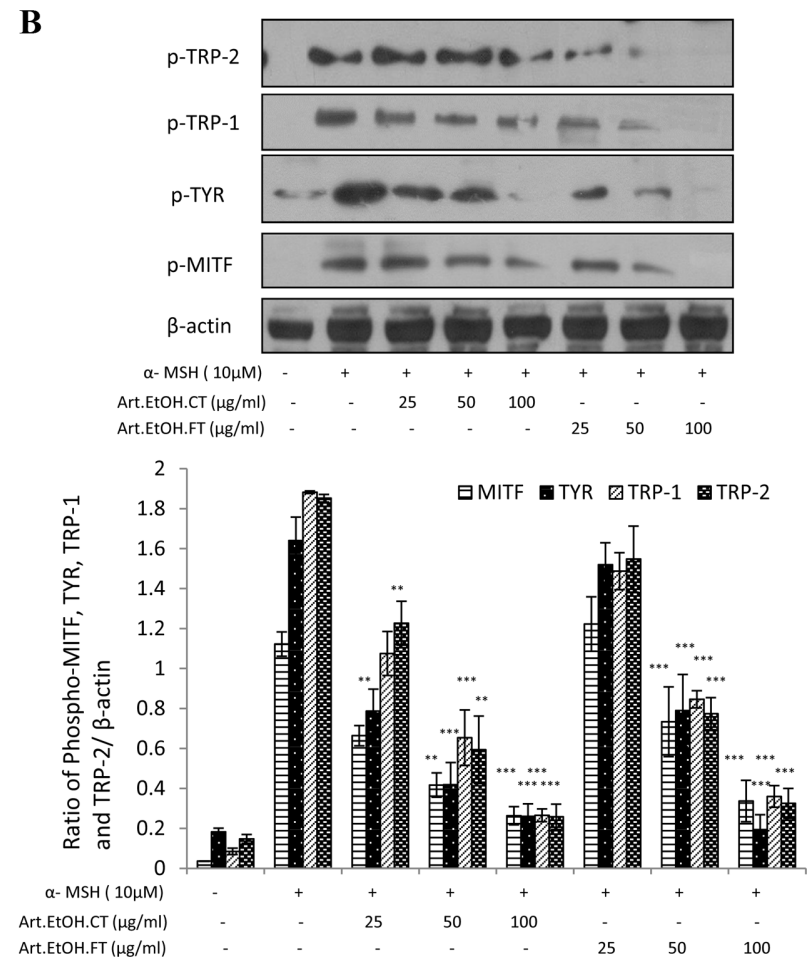

Fig. 4. A. capillaris extracts elicit their anti-melanogenic effects by extracellular signal-regulated kinase (ERK) dependent MITF pathway. B16/F10 cells were treated with both extracts at indicated concentrations and then stimulated with $\alpha-\mathrm{MSH}(10 \mu \mathrm{M})$. Whole cell lysates were then subjected to Western-blot analysis using antibodies against phospho-specific mitogen-activated protein kinase kinase (p-MEK) and phospho-specific ERK (p-ERK) compared against their total forms (A). Similarly antibodies against MITF, TYR, TRP1 and TRP-2 were also analysed (B). $\beta$-actin was taken as an internal control for MITF downstream factors. ${ }^{* * *} p<0.001$ and ${ }^{* *} p<0.05$ were considered as statistically significant against $\alpha$-MSH treated group only.

called melanocytes that synthesize and transport melanin to the adjacent keratinocytes thereby forming a uniform layer of skin pigmentation. The key function of these melanin pigments are two. First one is to give colour to skin and second one is to protect the skin from harmful ultraviolet radiations by reducing the amount of reactive oxygen species [6]. Upon exposure of keratinocytes to ultraviolet, melanogenesis starts and the most potent entity that is secreted is the $\alpha$-MSH hormone that activates melanin production in melanocytes [22]. Furthermore, MITF that is the transcriptional factor for the regulation of TYR, TRP-1 and TRP-2 is a critical factor for the production of melanin $[9,14,25]$.

It has also been reported that ERK is an important regulator of MITF since its activation causes the phosphorylation and degradation of MITF, thus causing inhibition in melanin production $[8,31]$. There are various studies in past that have shown the role of ERK in directly acting upon MITF for example Kim et al. [11, 12] in 2003 and 2007 reported the anti-melanogenic effects of sphingosine-1-phosphate and KHG 22394 (i.e., 2-imino-1,3-thiazoline derivative) on B16/F10 cells following the same procedures like our study but some studies on natural products have also represented their product's anti-melanogenic effects which do not involve the ERK activated MITF pathways [13]. However, in our study both A. capillaris samples had potently followed the ERK medi- ated MITF pathway for manifestation of their anti-melanogenic effects. The fermented type A. capillaris showed more potent activity as compared to non-fermented type based on GC-MS for these two extracts. Higher levels of acetic acid were found in fermented type extract (i.e., $40 \%$ vs. $18 \%$ in non-fermented type extract). Moreover, the amount of deoxy arteminisin was also higher in fermented type (i.e., 7\% vs. $5 \%$ in non-fermented type).

Kojic acid is considered to be the most abundantly and potently available synthetic inhibitor of melanin synthesis via TYR suppression [35]. It is considered to be the necessary component of cosmetics related to skin whitening and hypopigmentation. However, most of kojic acid and its derivatives are not oil soluble and are unstable at higher temperatures [21]. Since numerous studies have been carried out to develop and characterize TYR inhibitors from natural herbal sources $[18,26,28]$, in this context we also geared to explore the effects of $A$. capillaris fermented and non-fermented ethanol extracts on B16/F10 cells stimulated with $\alpha$-MSH. Our results clearly demonstrated that both extracts used in our study inhibited the TYR activity in cell free system and suppressed the melanin synthesis without any cytotoxicity.

Since the anti-melanogenic effects of $A$. capillaris can be elicited by various pathways, we therefore checked the transcriptional levels of the genes related to MITF pathway that 
is the most obvious pathway for the melanin synthesis. Our results showed that both extracts were more potent in the fermented type and diminished the expression levels of MITF, TYR, TRP-1 and TRP-2 in a dose dependent manner. Furthermore since ERK factor from MAPK pathway would be also involved in the activation of MITF, we checked the expression levels of MEK and ERK in the presence of samples and showed the activation of both MEK and ERK in a dose dependent manner. Next we investigated the expression levels of MITF and its downstream factors that were also found to be dose dependently suppressed in phosphorylation levels by $A$. capillaris samples, strongly indicating that it follows ERK dependent MITF pathway for eliciting its antimelanogenic effects. With further in vivo studies for mouse melanogenic models, we can guarantee that $A$. capillaris fermented type sample can be inculcated in the cosmetic industry as a potent skin whitening agent.

\section{Acknowledgments}

This research was supported by the National Research Foundation of Korea grant funded by the Korean Government (2015R1D1A1A09057204).

\section{References}

1. Aniya Y, Shimabukuro M, Shimoji M, Kohatsu M, Gyamfi MA, Miyagi C, Kunii D, Takayama F, Egashira T. Antioxidant and hepatoprotective actions of the medicinal herb Artemisia campestris from the Okinawa Islands. Biol Pharm Bull 2000, 23, 309-312.

2. Brenner M, Hearing VJ. The protective role of melanin against UV damage in human skin. Photochem Photobiol 2008, 84, 539-549.

3. Cha JD, Moon SE, Kim HY, Cha IH, Lee KY. Essential oil of Artemisia capillaris induces apoptosis in $\mathrm{KB}$ cells via mitochondrial stress and caspase activation mediated by MAPK-stimulated signaling pathway. J Food Sci 2009, 74, T75-81.

4. Chevallier A. The Encyclopedia of Medicinal Plants. p. 170, Dorling Kindersley, St. Leonards, 1996.

5. dela Peña IJI, Hong E, Kim HJ, de la Peña JB, Woo TS, Lee YS, Cheong JH. Artemisia capillaris Thunberg produces sedative-hypnotic effects in mice, which are probably mediated through potentiation of the $\mathrm{GABA}_{\mathrm{A}}$ receptor. Am J Chin Med 2015, 43, 667-679.

6. Englaro W, Bertolotto C, Buscà R, Brunet A, Pagès G, Ortonne JP, Ballotti R. Inhibition of the mitogen-activated protein kinase pathway triggers B16 melanoma cell differentiation. J Biol Chem 1998, 273, 9966-9970.

7. Han KH, Jeon YJ, Athukorala Y, Choi KD, Kim CJ, Cho JK, Sekikawa M, Fukushima M, Lee CH. A water extract of Artemisia capillaris prevents 2,2'-azobis(2-amidinopropane) dihydrochloride-induced liver damage in rats. J Med Food 2006, 9, 342-347.

8. Hemesath TJ, Price ER, Takemoto C, Badalian T, Fisher DE. MAP kinase links the transcription factor Microphthalmia to c-Kit signalling in melanocytes. Nature 1998, 391, 298-
301.

9. Hu YH, Liu X, Jia YL, Guo YJ, Wang Q, Chen QX. Inhibitory kinetics of chlorocinnamic acids on mushroom tyrosinase. J Biosci Bioeng 2014, 117, 142-146.

10. Joshi RK. Artemisia capillaris: medicinal uses and future source for commercial uses from western Himalaya of Uttrakhand. Asian J Res Pharm Sci 2013, 3, 137-140.

11. Kim DS, Hwang ES, Lee JE, Kim SY, Kwon SB, Park KC. Sphingosine-1-phosphate decreases melanin synthesis via sustained ERK activation and subsequent MITF degradation. J Cell Sci 2003, 116, 1699-1706.

12. Kim DS, Jeong YM, Park IK, Hahn HG, Lee HK, Kwon SB, Jeong JH, Yang SJ, Sohn UD, Park KC. A new 2imino-1,3-thiazoline derivative, KHG22394, inhibits melanin synthesis in mouse B16 melanoma cells. Biol Pharm Bull 2007, 30, 180-183.

13. Kim DS, Kim SY, Park SH, Choi YG, Kwon SB, Kim MK, Na JI, Youn SW, Park KC. Inhibitory effects of 4-nbutylresorcinol on tyrosinase activity and melanin synthesis. Biol Pharm Bull 2005, 28, 2216-2219.

14. Kim HR, Kim H, Jung BJ, You GE, Jang S, Chung DK. Lipoteichoic acid isolated from Lactobacillus plantarum inhibits melanogenesis in B16F10 mouse melanoma cells. Mol Cells 2015, 38, 163-170.

15. Kim JY, Lee JY, Lee WY, Yi Y, Lim Y. Anti-oxidant property and inhibition of melanin synthesis of eight plant extracts. Korean J Microbiol Biotechnol 2010, 38, 414-419.

16. Kim YI, Lee JH, Park SW, Choi IH, Friedman SL, Woo HJ, Kim YC. Artemisia capillaris Thunb. inhibits cell growth and induces apoptosis in human hepatic stellate cell line LX2. Orient Pharm Exp Med 2010, 10, 254-262.

17. Kim YS, Bahn KN, Hah CK, Gang HI, Ha YL. Inhibition of 7,12-dimethylbenz[a]anthracene induced mouse skin carcinogenesis by Artemisia capillaris. J Food Sci 2008, 73, T1620.

18. Komiyama K, Takamatsu S, Takahashi Y, Shinose M, Hayashi M, Tanaka H, Iwai Y, Omura S, Imokawa G. New inhibitors of melanogenesis, OH-3984 K1 and K2. I. Taxonomy, fermentation, isolation and biological characteristics. J Antibiot (Tokyo) 1993, 46, 1520-1525.

19. Koo HN, Hong SH, Jeong HJ, Lee EH, Kim NG, Choi SD, Ra KW, Kim KS, Kang BK, Kim JJ, Oh JG, Kim HM. Inhibitory effect of Artemisia capillaris on ethanolinduced cytokines (TNF- $\alpha$, IL-1 $\alpha$ ) secretion in Hep G2 cells. Immunopharmacol Immunotoxicol 2002, 24, 441-453.

20. Kwon OS, Choi JS, Islam MN, Kim YS, Kim HP. Inhibition of 5-lipoxygenase and skin inflammation by the aerial parts of Artemisia capillaris and its constituents. Arch Pharm Res 2011, 34, 1561-1569.

21. Lajis AFB, Hamid M, Ariff AB. Depigmenting effect of kojic acid esters in hyperpigmented B16F1 melanoma cells. J Biomed Biotechnol 2012, 2012, 952452.

22. Lee HJ, Lee WJ, Chang SE, Lee GY. Hesperidin, a popular antioxidant inhibits melanogenesis via Erk1/2 mediated MITF degradation. Int J Mol Sci 2015, 16, 18384-18395.

23. Lee MK, Choi GP, Ryu LH, Lee GY, Yu CY, Lee HY. [Enhanced immune activity and cytotoxicity of Artemisia capillaris Thunb. extracts against human cell lines]. Korean J Med Crop Sci 2004, 12, 36-42. Korean.

24. Liu ZL, Chu SS, Liu QR. Chemical composition and 
insecticidal activity against Sitophilus zeamais of the essential oils of Artemisia capillaris and Artemisia mongolica. Molecules 2010, 15, 2600-2608.

25. Masamoto Y, Ando H, Murata Y, Shimoishi Y, Tada M, Takahata K. Mushroom tyrosinase inhibitory activity of esculetin isolated from seeds of Euphorbia lathyris L. Biosci Biotechnol Biochem 2003, 67, 631-634.

26. Momtaz S, Mapunya BM, Houghton PJ, Edgerly C, Hussein A, Naidoo S, Lall $\mathbf{N}$. Tyrosinase inhibition by extracts and constituents of Sideroxylon inerme L. stem bark, used in South Africa for skin lightening. J Ethnopharmacol 2008, 119, 507-512.

27. Ohguchi K, Tanaka T, Iliya I, Ito T, Iinuma M, Matsumoto K, Akao Y, Nozawa Y. Gnetol as a potent tyrosinase inhibitor from genus Gnetum. Biosci Biotechnol Biochem 2003, 67, 663-665.

28. Roh JS, Han JY, Kim JH, Hwang JK. Inhibitory effects of active compounds isolated from safflower (Carthamus tinctorius L.) seeds for melanogenesis. Biol Pharm Bull 2004, 27, 1976-1978.

29. Saba E, Lee CH, Jeong DH, Lee K, Kim TH, Roh SS, Kim SH, Rhee MH. Fermented rice bran prevents atopic dermatitis in DNCB-treated NC/Nga mice. J Biomed Res 2016, 30, 334-343.

30. Seo KS, Jeong HJ, Yun KW. Antimicrobial activity and chemical components of two plants, Artemisia capillaris and Artemisia iwayomogi, used as Korean herbal Injin. J Ecol Field Biol 2010, 33, 141-147.

31. Shen T, Heo SI, Wang MH. Involvement of the p38
MAPK and ERK signaling pathway in the anti-melanogenic effect of methyl 3,5-dicaffeoyl quinate in B16F10 mouse melanoma cells. Chem Biol Interact 2012, 199, 106-111.

32. Tan RX, Zheng WF, Tang HQ. Biologically active substances from the genus Artemisia. Planta Med 1998, 64, 295-302.

33. Uchida R, Ishikawa S, Tomoda H. Inhibition of tyrosinase activity and melanine pigmentation by 2-hydroxytyrosol. Acta Pharm Sin B 2014, 4, 141-145.

34. Wu M, Hemesath TJ, Takemoto CM, Horstmann MA, Wells AG, Price ER, Fisher DZ, Fisher DE. c-Kit triggers dual phosphorylations, which couple activation and degradation of the essential melanocyte factor Mi. Genes Dev 2000, 14, 301-312.

35. Xie W, Zhang J, Ma X, Yang W, Zhou Y, Tang X, Zou Y, Li H, He J, Xie S, Zhao Y, Liu F. Synthesis and biological evaluation of kojic acid derivatives containing 1,2,4-triazole as potent tyrosinase inhibitors. Chem Biol Drug Des 2015, 86, 1087-1092.

36. Yokota T, Nishio H, Kubota Y, Mizoguchi M. The inhibitory effect of glabridin from licorice extracts on melanogenesis and inflammation. Pigment Cell Res 1998, 11, 355-361.

37. Yoon HS, Ko HC, Kim SS, Park KJ, An HJ, Choi YH, Kim SJ, Lee NH, Hyun CG. Tangeretin triggers melanogenesis through the activation of melanogenic signaling proteins and sustained extracellular signal-regulated kinase in B16/F10 murine melanoma cells. Nat Prod Commun 2015, 10, 389-392. 